\title{
Revista Colombiana de

\section{Evaluación económica de stents coronarios en pacientes con infarto del miocardio con elevación del ST en Colombia: un paso hacia la implementación de políticas}

\section{Economic assessment of coronary stenting in patients with ST elevation myocardial infarction in Colombia: A step toward policy implementation}

\author{
Jaime Murillo \\ $M D, F A C C, F A S E$. \\ Recibido el 17 de noviembre de 2014; aceptado el 20 de noviembre de 2014 \\ Disponible en Internet el 22 de enero de 2015
}

El control de los gastos de la atención médica sigue siendo uno de los retos más importantes que muchos países del mundo están afrontando actualmente, debido a su potencial de afectar la prestación de servicios básicos de atención de la salud dentro de la próxima década. Como se observa en este gráfico del Banco Mundial (fig. 1), el gasto en salud per cápita en Colombia, ha seguido la misma tendencia al alza observada en la mayoría de los países más desarrollados y en vía de desarrollo ${ }^{1}$.

Puesto que la enfermedad cardiovascular sigue siendo la principal causa de morbimortalidad, cualquier intervención a gran escala tendrá un impacto significativo en los presupuestos sanitarios.

El análisis de costo-efectividad es una herramienta que ofrece diferentes costos asociados con los resultados de salud, compara los costos de las alternativas de tratamiento y evalúa qué alternativa vale la pena en cuanto al costo. Esta información proporcionará a los diseñadores de políticas

\footnotetext{
Véase contenido relacionado en DOIs: http://dx.doi.org/10.1016/j.rccar.2014.11.005, http://dx.doi.org/10.1016/j.rccar.2014.06.005

is Este artículo está disponible en inglés en: www.elsevier.es/revcolcar

Correo electrónico: jaime.murillo@me.com
}

elementos para las decisiones de asignación de recursos. El objetivo es conseguir el máximo rendimiento de los recursos financieros existentes y proyectados.

Los años de vida ajustados por calidad, o AVAC, reflejan el número de años de vida de alta calidad que gana un paciente con una intervención determinada. Otro parámetro utilizado para medir su valor es la relación costo-efectividad. Este es el precio de comprar años más saludables con un nuevo tratamiento, en comparación con el tratamiento estándar, y si este es relevante.

La Organización Mundial de la Salud tiene una regla de oro: una intervención es costo-efectiva cuando cada año de vida ganado de vida ajustada por calidad equivale a tres veces el ingreso de una persona al año.

Para lograr más avances en materia de salud, enfrentar nuevos desafíos y corregir las desigualdades, los recursos deben utilizarse eficazmente. Esto requiere conocimiento acerca de qué intervenciones funcionan realmente, información sobre cuánto cuestan, y experiencia en su aplicación y prestación.

En este número de la Revista Colombiana de Cardiología, M. Ceballos-González ${ }^{2}$ publicó un elegante análisis sobre costo-efectividad de los stents liberadores de fármacos (SLF) en comparación con los stents convencionales en pacientes con infarto del miocardio con elevación del ST (IAMEST) en Colombia. Sus análisis incluyeron los costos finales, los 


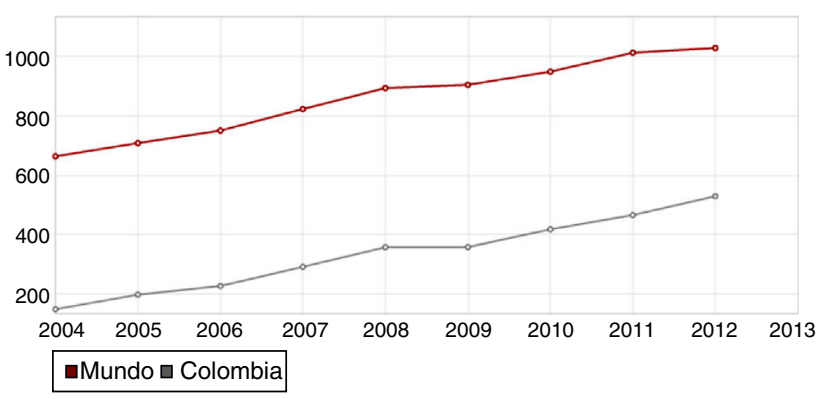

Figura 1 Gráfico del Banco Mundial.

costos proyectados, las determinaciones de probabilidad, así como muchos otros cálculos que son bastante difíciles de traducir a lenguaje clínico. Sin embargo, la conclusión principal fue que los stents liberadores de sirolimus no son costo-efectivos para los pacientes con IAMEST en Colombia.

Es importante recordar que este análisis se circunscribe a los pacientes con IAMEST y no se aplica a las intervenciones electivas o semielectivas. La prevalencia tiene un gran efecto en el análisis de costo-efectividad. Por ejemplo, el tamizaje y el tratamiento del Helicobacter, un factor de riesgo bacteriano para el cáncer de estómago, no es costoefectivo en los Estados Unidos, pero sí lo es en Colombia, debido a que la prevalencia de cáncer de estómago es más alta en este país y a que muchos de los costos del tratamiento son más bajos. Por esta razón, es importante no extrapolar necesariamente los resultados de IAMEST a la colocación de stents de forma electiva o semielectiva, ya que la prevalencia y la tasa de complicaciones son diferentes. Además, las características del paciente y de las lesiones pueden ser más relevantes al determinar la elección de los stents convencionales frente a los liberadores de drogas, que la consideración actual de la prevalencia de la enfermedad arterial coronaria.

La evolución de los precios también puede hacer la diferencia entre costo-efectivo y no costo-efectivo. Un estudio publicado por Barone-Rochette et al. ${ }^{3}$ encontró que los stents sirolimus no fueron costo-efectivos en 2008, pero sí lo fueron en 2012 después de que su precio se redujo.

Como política de salud, la recomendación de evitar SLF en el escenario de un IAMEST en Colombia puede parecer razonable desde el punto de vista económico. Sin embargo, es importante recordar que las políticas son directrices y no necesariamente se aplican a cada caso determinado. Al tomar la decisión de usar stents medicados vs. stents convencionales es importante hacer reflexiones individuales en cada paciente, tales como la «compliance», el tipo de lesión, las enfermedades concurrentes que pueden aumentar el riesgo de reestenosis (diabéticos), etc. En este estudio, las complicaciones tardías superaron el beneficio inicial del SLF. No se puede excluir que las complicaciones tardías fueran debidas, por ejemplo, a la falta de «compliance» con la terapia antiplaquetaria.

Este estudio puede ayudar a crear un incentivo hacia el delineamiento de las políticas de salud en torno al manejo de los IAMEST, lo que ayudará a estandarizar los tratamientos en todas las regiones e instituciones. Existen grandes variaciones en la frecuencia con la que los médicos ordenan pruebas, prescriben medicamentos, hacen procedimientos o cirugías, no solo en diferentes partes del país, sino también en los hospitales que están uno al lado del otro. En un lugar se pueden hacer más procedimientos de un tipo en particular que los que se hacen en el que queda al lado.

Si pudiéramos conseguir que los hospitales de alto gasto/pobre rendimiento o regiones o áreas de servicios fueran más como los de menor gasto/mejores resultados, el sistema de salud podría ahorrar dinero y mejorar la salud al mismo tiempo.

Si hay una lección para aprender del sistema de salud estadounidense es que los elevados costos de atención de salud no son sostenibles en el largo plazo y que encontrar el equilibrio entre los costos y los resultados beneficiará tanto a los pacientes como a los proveedores.

\section{Bibliografía}

1. Disponible en: http://data.worldbank.org/indicator/SH.XPD. $\mathrm{PCAP} /$ countries/1W-CO?display=graph

2. Ceballos González, Evaluación económica del stent medicado comparado con el convencional para pacientes con infarto agudo al miocardio con elevación del ST en Colombia.

3. Barone-Rochette G, Machecourt J, Vanzetto G, Foote A, Quesada JL, Castelli C, et al., EVASTENT investigators. The favorable price evolution between bare metal stents and drug eluting stents increases the cost effectiveness of drug eluting stents. Int J Cardiol. 2013;168(2):1466-71. 